\title{
Reinforcing effect of an informative stimulus that is not a positive discriminative stimulus '
}

\author{
DEREK P. HENDRY, UNIVERSITY OF ILLINOIS, CHICAGO CIRCLE

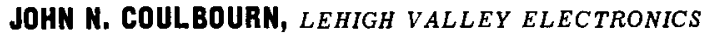

A stimulus associated with non-reinforcement is reinforcing when it predicts reinforcement.

Prompted by the studies of Egger \& Miller (1962, 1963), we tried to specify what made a stimulus informative. We concluded that "informative" refers to a relation between one stimulus and at least one other stimulus. Stimulus $A$ is informative about stimulus $B$ to the extent that occurrence of $A$ makes possible a more accurate prediction of the occurrence of $B$. We carried out several experiments to test Egger and Miller's hypothesis that a stimulus informative about a reinforcer would be a conditioned reinforcer. However, our colleagues always found a way of interpreting the stimuli that we called informative as conventional discriminative stimuli whose reinforcing effect, except in a few well-known cases, is generally accepted (cf., Kelleher \& Gollub, 1962). Moreover, they usually insisted that the concept of an informative stimulus was equivalent to the concept of discriminative, or controlling, stimulus. Repeated encounters with this point of view eventually prompted us to design an experiment, described here, that would allow us to distinguish discriminative and informative functions of a stimulus, and that would show whether the informative stimulus was a conditioned reinforcer.

Method

A standard pigeon chamber was used. Three mature white Carneaux pigeons, maintained at $75 \%$ of freefeeding weight, were exposed for upwards of $1 \mathrm{hr}$. per session to the situation depicted, according to the notation of Mechner (1959), in Fig. 1. The birds had not taken part in any other experiment and were not specifically trained to peck the key in this experiment.

What happens if the bird makes no pecks is easily discovered by following the successive arrows from one " $\mathrm{T}$ " to the next in Fig. 1. On negative trials, after 65 sec. $(\mathrm{T} 30+\mathrm{T} 35)$ the key turns green for 10 sec. $(5+$ 5). On positive trials, after 65 sec. the key turns red for 10 sec., during the last 5 of which the feeder is operated. After a 15-sec. blackout $\left(\mathrm{S}_{\mathrm{TO}}\right)$ the key turns white as the next cycle begins.

Responses on the key have no effect on negative trials. On positive trials the first key-peck between 30 and $45 \mathrm{sec}$. after the end of the blackout changes the key from white to green for $5 \mathrm{sec}$. No other responses have any effect. The key turns white again after the $5 \mathrm{sec}$. green stimulus. At least $15 \mathrm{sec}$. later (when T35 times out) the key turns red for 10 sec.s with the feeder operating during the final $5 \mathrm{sec}$.

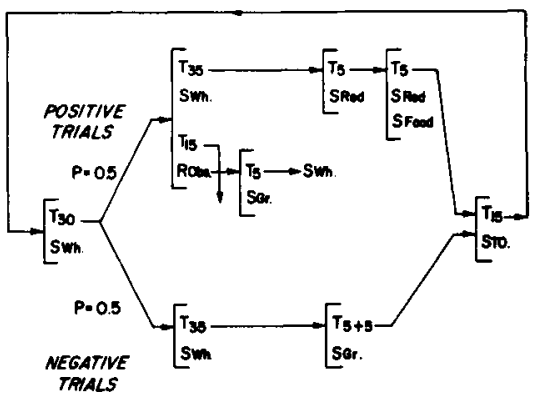

SWh.-WHITE

SRed - RED

KEY KEY SGr.-GREEN KEY

STO.- BLACK - OUT

Fig. 1. Procedure. See text.

Note that the bird does not have to key-peck to receive food, there is no advantage in frequency or number of reinforcements from key-pecking, and the imminence of food presentation is signified (by the key's being red) whether or not the bird key-pecks.

A red key always precedes and accompanies presentation of food at the end of a positive trial and a green key always accompanies the corresponding absence of food in a negative trial. Thus, by well-established convention, a red key is a positive discriminative stimulus, or $\mathrm{s}^{\mathrm{D}}$, and a green key is a negative discriminative stimulus, or $S^{\Delta}$, for the behavior of obtaining the food from the feeder (though not for key-pecking). However, the response-produced green key is informative in that it predicts food presentation. The temporal relation to the presentation of food of a response-produced green key is less variable than that of a white key.

After responding was established, food was omitted for four sessions. After five further sessions, the green informative key could not be obtained by key-pecking for six sessions. For five final sessions, the green key could again be obtained.

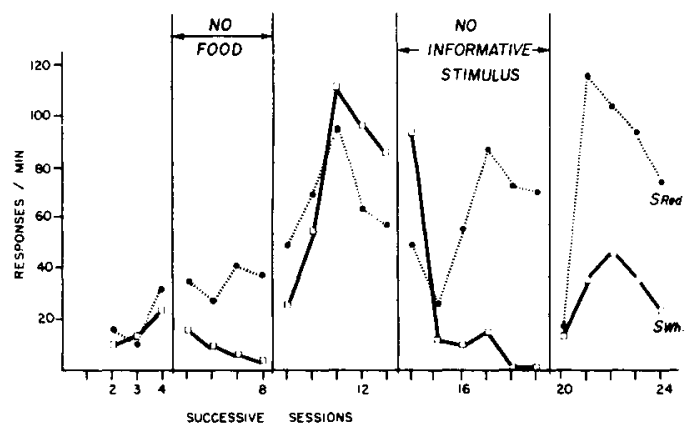

Fig. 2. Rate of pecking the response key when it was red for 5 sec. before presentation of food $\left(S_{R_{e d}}\right)$ and when it was white $\left(S_{W h}\right)$. No data were obtained for session 1. 

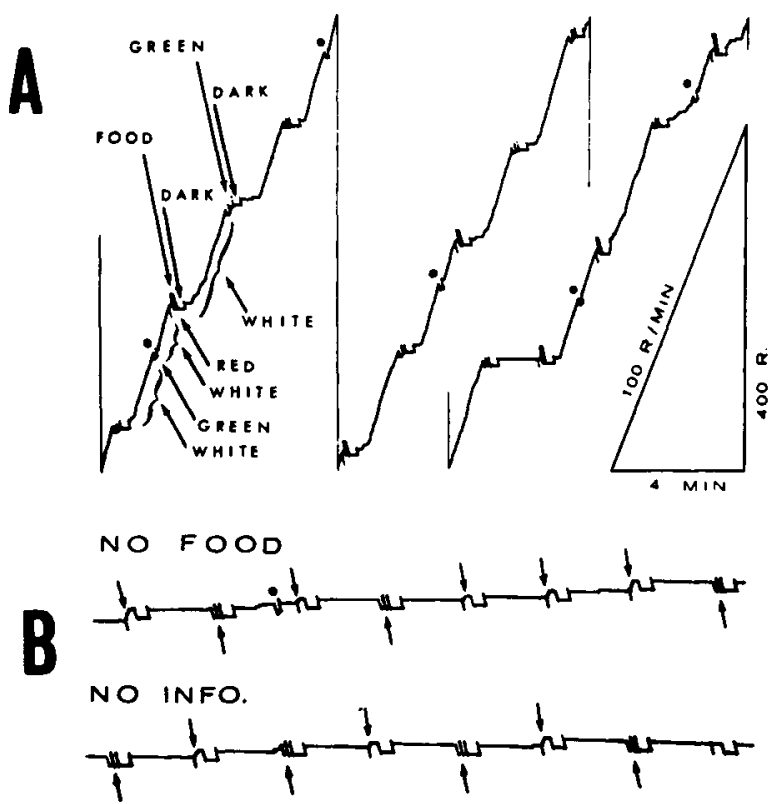

Fig. 3. A. Typical performance from session 12. Presentation of food is shown by heavy hatch marks; the preceding pip indicates onset of the prefood stimulus, a red key; the succeeding downward pen displacement indicates occurrence of the blackout or inter-trial interval. Trials not terminated with food were terminated with a 10 sec. green key, followed by the inter-trial interval, shown in that case as a downward pen displacement with two upward pips. The first upward pip occurred after the key had been green for 5 sec. and the second upward pip occurred 5 sec. later as the green light went off. Occurrences of a response-produced green key are indicated by dots opposite the pen deflections. The key colors are indicated for the first two trials. B. Results of the two extinction procedures described in the text. The upper trace is from session 7, and the lower trace from session 16 . The heavy hatch for food presentation has been omitted. The downward-pointing arrows indicate responses to the red key. The upward-pointing arrows indicate the pre-blackout green key, to which no responses occur.

\section{Results and Discussion}

One bird made not a single peck on the response key during the experiment. This is the normally expected result, since no preliminary training was given. Since no responses occurred, the results from this bird have no bearing on the main questions of the experiment. Another bird did learn to peck the key butdied half-way through the experiment. The bird completed 11 sessions, with results substantially the same, up to that point, as those of the third bird. Only the results for the third bird, which are quite convincing, will be presented in detail.

Once responding was established, the red, pre-food stimulus evidently exerted considerable control. The bird responded on the red key until reinforcement was delivered. There seems little doubt that key-pecking was superstitiously reinforced, both by the presentation of food and the red key. Figure 2 shows the differential effect of the procedures on response rate on the key when red and when white. Responding extinguished when the food was omitted, except to the red key. This result might be taken to show that all responding was superstitiously maintained by the occasional presentation of food, and that responding on the red key was simply more resistant to extinction because of having been more closely associated with the presentation of food. However, the untenability of that interpretation is demonstrated by the effect, also shown in Fig. 2, of removing the informative stimulus. When the informative stimulus was removed, responding extinguished except to the red key. The maintenance of responding to the redkey confirms that pecking the red key was superstitiously reinforced and therefore that the red key was acting as $\mathrm{SD}$ for key-pecking, but the simultaneous extinction of responding to the white key shows that pecking the white key was not maintained by the (superstitious) production of the red key, but was maintaned by the production of the informative, green key.

The independent reinforcing effect of the green key was indicated by the appearance of fixed-interval-like schedule control (cf., Kelleher, 1966) in the successive accelerations of response rate-first up to the occurrence of the green key, then up to the occurrence of the red key, as illustrated in Fig. 3A.

Figure 3B shows essentially identical performance as a result of the two kinds of extinction procedures. In both cases several responses occur to the key when it turns red, but few responses occur at other times, to a green or a white key.

These results show that a stimulus may become a conditioned reinforcer without being closely associated in time with a reinforcer and without being the occasion for a reinforced response. The simplest expression and interpretation of the results seems to be that the response-produced green key was a conditioned reinforcer by virtue of its informative, or predictive, function.

\section{References}

Egger, M. D., \& Miller, N. E. Secondary reinforcement in rats as a function of information value and reliability of the stimulus. $J$. exp. Psychol., 1962, 64, 97-104.

Egger, M. D., \& Miller, N. E. When is reward reinforcing?: an experimental study of the information hypothesis. J. comp. physiol. Psychol., 1963, 56, 132-137.

Kelleher, R. T. Conditioned reinforcement in second-order schedules. J. exp. Anal. Behav., 1966, 9, 475-485.

Kelleher, R. T., \& Gollub, L. R. A review of positive conditioned reinforcement. J. exp. Anal. Behav., 1962, 4, 543-597.

Mechner, F. A notation system for the description of behavioral procedures. J. exp. Anal. Behav., 1959, 2, 133-150.

\section{Note}

1. Supported by grants from NASA (NsG 189-61) and USPHS (GM14221). 